\title{
Development of an application for mobile devices to identify the frailty phenotype among the elderly
}

\section{Abstract}

Objective: to develop a mobile app to quickly and safely identify frailty syndrome features among the elderly. Method: a cross-sectional study was conducted. The application was developed for the Android platform in the Java programming language and XML markup. The study instrument was based on five frailty phenotype criteria. The tests were conducted with 20 elderly persons living in a long-term care facility. Results: the twenty elderly persons had a mean age of $76.55( \pm 9.5)$ years. Thirteen were identified as frail, five were pre-frail and two were non-frail. The comparison of the results of the instruments of analysis coincided in the general evaluation of frailty and in the individual identification of the five criteria. Conclusion: the data suggests that the use of the application for the evaluation of frailty among the elderly was performed safely, with the advantage of quick access to allow the monitoring of the clinical status and prognosis of the patient.
Thassyane Silva dos Santos'

Thais Alves Brito ${ }^{1}$

Francisco Sadao Yokoyama Filho ${ }^{1}$

Lara de Andrade Guimarães'

Caroline Sampaio Souto ${ }^{1}$

Samara Jesus Nascimento Souza ${ }^{1}$

Luiz Eduardo Barreto Martins² Karla Rocha Pithon'
Keywords: Software Validation. Elderly. Frail Elderly. Computer Systems. Decision Making, ComputerAssisted.

\footnotetext{
Universidade Estadual do Sudoeste da Bahia, Departamento de Saúde I. Jequié, Bahia, Brasil.

2 Universidade Estadual de Campinas, Departamento de Ciências do Esporte, Faculdade de Educação Física. Campinas, São Paulo, Brasil. 


\section{INTRODUCTION}

Frailty is a multifactorial geriatric clinical syndrome characterized by declining energy reserves, neuroendocrine dysregulation, impaired immune system functioning and decreased resistance to stressors ${ }^{1}$.

The integration of these factors, coupled with the reduced self-regulation and homeostasis efficiency that is common in senescence, make the health of the elderly vulnerable ${ }^{2}$. The interpretation and early diagnosis of indicators related to the physiological and pathological functional decline associated with aging should be prioritized to ensure a more effective intervention ${ }^{3}$.

New information technologies are constantly emerging, several of which have been integrated into the area of health. These instruments aim to increase access to health surveillance and clinical prediction data ${ }^{4}$. Thus, their use makes it possible to obtain indicators and create a population database for future epidemiological studies ${ }^{5}$, in addition to permitting the standardization of the data collected.

The development of an application arose as a strategy to introduce health professionals to the use of another instrument for measuring and diagnosing the health vulnerability of elderly individuals. Therefore, the objective of the present study was to develop an application for mobile devices in order to quickly and safely identify the characteristics of the syndrome of frailty among the elderly.

\section{METHOD}

A cross-sectional quantitative study was conducted of individuals aged over 60 years of age of both genders, who lived in a non-profit longterm care facility for the elderly (LTCFE). The initial population was composed of the 52 elderly persons residing in this LTCFE.

The study included elderly people who had lived in the LTCFE for more than six months; who did not suffer from cognitive deficit, evaluated by the Mini Mental State Exam; ${ }^{6}$ and who did not have permanent or temporary motor limitations that compromised the performance of walking tests (the use of walking stick or walker was allowed). The exclusion criteria were: localized loss of strength and aphasia due to severe cerebrovascular accident; severe impairments of speech motility; hearing loss or severe vision loss. All the elderly persons were approached and informed about the purpose and stages of the study.

After applying the eligibility criteria, 23 elderly persons were selected. Of these, two refused to perform some of the tests and one did not perform the hand grip test because of a fracture in the dominant upper limb. Therefore, the final sample of this study was composed of 20 elderly people. Data collection was carried out from March to October 2014.

The instrument of the study was based on the five criteria for the definition of the frailty phenotype described by Fried et al. ${ }^{1}$ : unintentional weight loss, self-reported fatigue, reduction of hand grip strength, low level of physical activity and reduction of gait speed. The researchers conducted the interviews personally with the volunteers, describing each test.

After data collection, four previously trained evaluators were divided into two pairs, one of which analyzed the data manually and the other used the application. The analyzes were performed independently and, if there were disagreements, the analysis was re-evaluated by a third evaluator. Data is presented as mean, standard deviation and relative and absolute frequency.

The study design was referred to the Ethics Committee for Human Research of the Universidade Estadual do Sudoeste da Bahia (the State University of the Southeast of Bahia), in accordance with National Health Council Resolution $n^{\circ} 466 / 12$. It was approved under record $n^{\circ}$ 393.466. Data collection only began following approval. The volunteers were subjected to the study protocol after signing a Free and Informed Consent Form. 


\section{Analysis of printed questionnaire}

The results were analyzed by the researchers based on predetermined cut-off points for each criterion. For non-intentional weight loss the criteria was weight loss of $\geq 4.5 \mathrm{~kg}$ or $\geq 5 \%$ of body weight from the previous year, without dieting; fatigue was indicated by the answers always or almost always to two items of the Center for Epidemiological Study - Depression (CES-D) ${ }^{7}$, which asks about the reduction of energy when carrying out tasks during the previous week ${ }^{8}$; hand grip strength was evaluated by the average, in kilogram-force (kgf), of three consecutive measurements with a dynamometer, adjusted for gender and body mass index (BMI); gait speed was measured by the mean of three consecutive times (in seconds) required to walk $4.6 \mathrm{~m}$ in a flat location at usual pace, with the means adjusted by gender and height; weekly energy expenditure in physical exercises and in domestic activities was measured through the translated version of the Minnesota Leisure Time Physical Activity Questionnaire (MLTPAQ) ${ }^{9}$, consisting of 57 items, adapted from the original questionnaire of 63 items $^{10}$, the cutoff was adjusted by gender: $<383 \mathrm{Kcal}$ for men and $<270 \mathrm{Kcal}$ for women.

The weekly energy expenditure calculation (WEE) used the specific metabolic equivalent of task (MET) of each activity. The evaluator consulted the individual MET score for each self-reported task described in the compendium of physical activity $^{11}$. As such WEE (kcal/min) $=0.0175(\mathrm{kcal}$. $\left.\mathrm{kg}^{-1} \mathrm{~min}\right) \times \mathrm{MET}^{-1} \mathrm{x}$ body weight $(\mathrm{kg})$.

After analyzing the results of the tests and the questionnaires, elderly persons who scored positively in three or more criteria were classified as frail, in one or two as pre-frail and, in none, not frail.

\section{Analysis with application}

The smartphone application was specifically developed for the Android platform (the operating system created by Google) and was named Frágil Mobi (Frail Mobile). When actively responding to the questionnaire in the application, the evaluators could cancel and correct responses at any stage.

Initially, the researcher registers her name and password in the application. He or she is then directed to a screen with all the steps of the test that should be performed with the patient. Data entry begins with the identification of the patient and, later, the calculation of BMI and the corresponding classification. In the second stage, the researcher inserts data about weight loss in the previous year, then feeling of fatigue is verified from the two questions of the geriatric depression scale. In the fourth stage the weekly metabolic expenditure rate is reported, indicating the accomplishment of each physical exercise and each domestic task, as well as the time in minutes spent on each activity in one week (Figure 1).

\begin{tabular}{|l|}
\hline \multicolumn{1}{|c|}{ Frágil Mobi } \\
\hline Identification of patient - BMI \\
\hline Unintentional weight loss \\
\hline Feeling of fatigue \\
\hline Physical activity \\
\hline Gait speed \\
\hline Hand grip \\
\hline See final result \\
\hline Return \\
\hline
\end{tabular}

BMI: body mass index

Figure 1: Reproduction of Frágil Mobi application screen. Jequié, Bahia. 2014. 
In the section on other activities, five exercises were added that were not included in the original questionnaire: hydrogymnastic/ water aerobic exercises, light exercise bicycle with light, moderate and vigorous effort, and circuit training with an aerobic movement and minimum rest, which were inserted based on inserted. The adjustments were calculated from the data entered during patient identification.

After completing the fields in each screen, the researcher confirmed the data entered and advanced through the steps. The data was automatically saved and transferred to the mobile device memory. The application also allowed the researcher to perform isolated evaluations of the tests, after completing the personal data, although the diagnosis of frailty was only displayed after completing the questionnaire.

\begin{tabular}{|c|c|c|}
\hline \multicolumn{3}{|c|}{ Frágil Mobi } \\
\hline \multicolumn{3}{|c|}{ Section I - Others } \\
\hline \multicolumn{3}{|c|}{1 - Hydrogymnastic, water aerobic } \\
\hline o No & $\mathrm{O}$ & Yes \\
\hline \multicolumn{3}{|c|}{2 - Exercise bike, light effort } \\
\hline o No & $\mathrm{O}$ & Yes \\
\hline \multicolumn{3}{|c|}{3 - Exercise bike, moderate effort } \\
\hline $\mathrm{O} \quad \mathrm{No}$ & $\mathrm{O}$ & Yes \\
\hline \multicolumn{3}{|c|}{4 - Exercise bike, vigorous effort } \\
\hline o No & $\mathrm{O}$ & Yes \\
\hline \multicolumn{3}{|c|}{$\begin{array}{l}5 \text { - Circuit training featuring aerobic movement } \\
\text { with minimum rest }\end{array}$} \\
\hline No & $\mathrm{O}$ & Yes \\
\hline Cancel & & Confirm \\
\hline
\end{tabular}

Figure 2. Reproduction of Frágil Mobi application screen. Jequié, Bahia. 2014.

\section{RESULTS}

The age of the 20 participants ranged from 62 to 91 years, with a mean of $76.55( \pm 9.5)$ years. In the stratification of the group based on the Fried criteria ${ }^{1}$, 13 elderly persons were considered frail, five were prefail and two were non-frail (Table 1). When considering the criteria individually, four of the 13 elderly persons considered frail had five positive criteria; four participants had four positive criteria and five had three positive criteria. The five pre-frail elderly persons had two positive criteria.

After the printed questionnaire was screened, the data was reassessed and analyzed with the application and the scores were compared. When compared, there was no difference in the evaluations obtained with the printed version and with the electronic version. The results coincided in all cases, both in the general evaluation of frailty and in the five individual criteria. In other words, the application agreed with the printed questionnaire, which is considered the gold standard.

The collected data was stored in the internal memory of the mobile device and the information could only be accessed through authorization via the login name and password of the health professional/researcher.

In the final sample, the patient's name was displayed with the initials of his or her first and last name, age, skin color/ethnicity, gender, body mass, height, BMI, the results of the five individual criteria and the conclusion: frail, prefrail and non-frail (Figure 3). 
Table 1. Results of frailty criteria. Jequié, Bahia. 2014.

\begin{tabular}{lll}
\hline Gender & Classification & n of elderly persons \\
\hline Men & Non-frail elderly persons & 2 \\
Women & & 0 \\
Men & Pre-frail elderly persons & 4 \\
Women & & 1 \\
\hline Men & Frail elderly persons & 8 \\
Women & & 5 \\
\hline
\end{tabular}

Table prepared by authors.

\begin{tabular}{|l|l|}
\hline \multicolumn{2}{|c|}{ Frágil Mobi } \\
\hline \multicolumn{2}{|c|}{ Final Result } \\
\hline Patient: & S Y \\
\hline Age: & 60 \\
\hline Skin color/ethnicity: & White/Caucasian \\
\hline Gender: & Male \\
\hline Weight: & 60.0 \\
\hline Height: & 1.74 \\
\hline BMI: & 19.81 \\
\hline Weight loss: & Negative Criteria \\
\hline Feeling of fatigue: & Negative Criteria \\
\hline Physical Activity: & Positive Criteria \\
\hline Gait Speed: & Negative Criteria \\
\hline Hand Grip: & Positive Criteria \\
\hline Conclusion & Pre-Frail Patient \\
\hline
\end{tabular}

Figure 3. Reproduction of Frágil Mobi application screen. Jequié, Bahia. 2014.

\section{DISCUSSION}

Elderly health surveillance, together with the detection of predisposing factors of diseases, is the key instrument in prevention strategies aimed at anticipating the occurrence of diseases and intervening directly in current and past pathologies, involving the patient in treatment and encouraging self-care ${ }^{12}$.

Frail individuals are more susceptible to adverse health prognoses, such as disability and hospitalization due to the reduction of stress-related regulation, which predispose them to the onset of chronic diseases, loss of physical functionality and cognitive deficit ${ }^{1-13}$. The monitoring of health conditions and the functional capacity of this population is crucial to the creation of a care and intervention plan $^{14}$.

Agrigoroaei and $\operatorname{Lachman}^{15}$ point out that, at this stage, there is an increased loss of intellectual functioning, motivation, social participation and subjective well-being. The combination of factors such as depression and/or losses with chronic diseases and functional disabilities is the main motivation described by the elderly for the ideation or attempt of suicide ${ }^{16}$. In such cases there is a need for effective care planning and clinical judgment that results in an improved prognosis and the resolution of the clinical picture, which can be associated with frailty.

In a study with health professionals regarding criteria to indicate frailty, it was noted that there were no uniformly determined criteria among such individuals, and that the data obtained was prone to subjectivity ${ }^{17}$, diverging from the most cited definitions in international literature ${ }^{1,18-21}$. The use of the application can help in the identification of parameters for the evaluation of frailty, to reach a consensual and homogeneous definition. 
Assessment of the degree of functional capacity should be performed with multidimensional instruments ${ }^{12}$, as health decline in old age encompasses multiple factors ${ }^{19}$.

The health system and care models must adapt to the recent scenario of population aging. Care should be provided in a continuous, preventive manner, ensuring a more diffuse quality of life and well-being ${ }^{22,23}$.

The implementation of other functionalities such as the hand grip test and the six-minute walk test are potential future focuses for this study, which aims to use software to perform all necessary measures for the classification of frail elderly persons.

In addition, more tools will be incorporated into the software to aid in differential diagnosis, such as anthropometric measures, waist and hip measurement, and the possibility of storing current and previous disease history and information about cardiovascular risk factors. In this way, the crossing of the results of the tests through the application, combined with the clinical examination, will result in a more comprehensive evaluation.

\section{REFERENCES}

1. Fried LP, Tangen CM, Walston J, Newman AB, Hirsch C, Gottdiener J, et al. Frailty in older adults: evidence for a phenotype. J Gerontol A Biol Sci Med Sci 2001; 56:M146-56.

2. Linck CL, Crossetti MG. [Fragility in the elderly: what has being produced by nursing]. Rev Gaúcha Enferm. 2011;32(2):385-93.

3. Neri AL, Yassuda MS, Araújo LF, Eulálio MC, Cabral BE, Siqueira ME, et al. Metodologia e perfil sociodemográfico, cognitivo e de fragilidade de idosos comunitários de sete cidades brasileiras: Estudo FIBRA. Cad Saúde Publica. 2013;29(4):778-92.

4. Santorelli G; Petherick ES; Wright J; Wilson B; Samiei $\mathrm{H}$; Cameron N; Johnson W. Developing prediction equations and a mobile phone application to identify infants at risk of obesity. PLoS One; 2013; 8(8): 71183.
Given the lack of a validated protocol to authenticate an application in the area of health, the present study followed protocols already established in previous studies on frailty ${ }^{1}$. This allows tests widely used in research to be applied in clinical and diagnostic practice. However, it is a limitation of the study that the application was tested only by the researchers.

\section{CONCLUSION}

The application was developed in support of a preventive strategy, as tests and protocols that are common in scientific research remain unusual in clinical care. Parameters of frailty, when identified early, can be minimized, hence the importance of early detection.

The mobile device test proved to be efficient in defining frailty, with the advantage of instant processing and access to information, as well as the presentation of the final result in a concise manner. The adoption of this method ensures a rapid diagnosis, which facilitates decision making, the monitoring of the clinical picture and the prognosis of the patient by the health professional.

5. Tomasia E; Facchinib LA; Osorioa A; Fassab AG. Aplicativo para sistematizar informações no planejamento de ações de saúde pública. Rev Saúde pública; 2003;37(6):800-6.

6. Brucki SM, Nitrini R, Caramelli P, Bertolucci $\mathrm{PH}$, Ivan H. Okamoto IH. Sugestões para o Uso do Mini-Exame do Estado Mental no Brasil. Arq Neuropsiquiatr; 2003;61(3-B):777-81.

7. Orme J, Reis J, Herz E. Factorial and discriminate validity of the Center for Epidemiological Studies depression (CES-D) scale. J Clin Psychol. 1986;42:28-33.

8. Almeida OP, Almeida SA. Confiabilidade da versão brasileira da Escala de Depressão Geriátrica (GDS) versão reduzida. Arq Neuropsiquiatr. 1999; 57(2B):421-6. 
9. Lustosa L, Pereira D, Dias R, Britto R, Parentoni A, Pereira L: Tradução e adaptação transcultural do Minnesota Leisure Time Activities Questionnaire em idosos. Geriatria \& Gerontologia 2011, 5(2):57-65.

10. Taylor H, Jacobs D, Schucker B, Knudsen J, Leon A, Debacker G. A questionnaire for the assessment of leisure time physical activities. J Chron Dis 1978; 31:741-55.

11. Powers SK, Howley ET. Fisiologia do exercício: teoria e aplicação ao condicionamento físico e ao desempenho. 6. ed. São Paulo: Manole, 2009.

12. Veras R. Envelhecimento, demandas, desafios e inovações. Rev Saúde Pública 2009;43(3):548-54.

13. Ferrucci L, Guralnik JM, Studenski S, Fried LP, Cutler Jr. GB, Walston JD. Designing randomized, controlled trials aimed at preventing or delaying functional decline and disability in frail, older persons: a consensus report. J Am Geriatr Soc 2004; 52:625-34.

14. Lustosa LP, Marra TA, Pessanha FPAS, Freitas JC, Guedes RC. Fragilidade e funcionalidade entre idosos frequentadores de grupos de convivência em Belo Horizonte, MG. Rev. Bras. Geriatr. Gerontol. 2013; 16(2):347-354.

15. Agrigoroaei S, Lachman ME. Cognitive functioning in midlife and old age: combined effects of psychosocial and behavioral factors. J Gerontol B Psychol Soc Sci 2011; 66 Suppl 1:1130-40.

16. Cavalcante, FG, Minayo, MCS. Estudo qualitativo sobre tentativas e ideações suicidas com 60 pessoas idosas brasileiras. Ciênc. saúde coletiva. 2015 [acesso em 13 set. 2016]; 20(6):1655-1666. Disponível em: http://www.scielo.br/scielo.php?pid=S1413$81232015000601655 \&$ script $=$ sci_abstract\&tlng=pt
17. Teixeira, INDO. Percepções dos profissionais de saúde sobre os critérios para indicar fragilidade no idoso. Arq. Ciênc. Saúde Unipar, Umuarama 2008; 12(2):127-132.

18. Rockwood K. Frailty and its definition: a worthy challenge. J Am Geriatr Soc 2005; 53(6):1069.

19. Hogan D, Macknight C, Bergman H. Models, definitions, and criteria of frailty. Aging Clin Exp Res 2003; 15(3)(supp):2-29.

20. Bergman H, Béland F, Karunananthan S, Humme LS, Hogan D, Wolfson C. Développement d'un cadrede travail pour comprendre et étudier la fragilité [Developing a Working Framework for Understanding Frailty]. Gerontol Soc 2004; 109:15-29.

21. Collard, RM, Comijs, HC, Naarding P, Penninx, BW, Milaneschi, Y, Ferrucci, L, Voshaar, RCO. Frailty as a Predictor of the Incidence and Course of Depressed Mood. Journal of the American Medical Directors Association. 2015;16(6):509-514.

22. Veras RP. Estratégias para o enfrentamento das doenças crônicas: um modelo em que todos ganham. Rev Bras Geriatr Gerontol. 2011;14(4):779-86.

23. Veras RP. Experiências e tendências internacionais de modelos de cuidado para com o idoso. Cienc Saude Coletiva. 2012;17(1):231-8. 